\title{
Impacts of air drying and DIC pretreatments on textural properties of frozen/thawed apple fruits.
}

\author{
Ben Haj Said, L..$^{a}$; Bellagha, S. ${ }^{{ }^{*}}$; Allaf, K. ${ }^{\text {b }}$ \\ a Laboratory of valorization of natural heritage and Tunisian food through innovation, National \\ Institute of Agronomy of Tunisia, University of Carthage, 43, Avenue Charles Nicolle, 1082, Tunis \\ Mahrajene, Tunisia \\ ${ }^{\mathrm{b}}$ Laboratory of Engineering Science for Environment (LaSIE), UMR 7356 CNRS. Faculty of Science \\ and Technology, University of La Rochelle, avenue Michel Crepeau, 17042 La Rochelle cedex 01, \\ France.
}

*E-mail of the corresponding author: bellagha.sihemb@gmail.com

\begin{abstract}
This research work is about dehydrofreezing assisted by DIC treatment as an innovative conservation process of apple fruits. Samples previously dehydrated and DIC treated were frozen at $-30{ }^{\circ} \mathrm{C}$ and at two different practical freezing rates. The effects of sample water content (W) and practical freezing rate (PFR) on freezing characteristics and apple texture were examined. Thaw exudate water (TEW) of $200 \%$ and $100 \%$ db samples was approximately $3 \mathrm{~g} / 100 \mathrm{~g}$ water. Whereas, it was lower than $0.5 \mathrm{~g} / 100 \mathrm{~g}$ water for samples with $30 \% d b \mathrm{~W}$ during thawing at $4{ }^{\circ} \mathrm{C}$. Moreover, the impact of PFR on TEW was significant and very important only for high $W$ samples. For samples whose water content was lower than $100 \% d b$, firmness was as higher as the $W$ was lower, without any significant impact of PFR.
\end{abstract}

Keywords: Dehydrofreezing; Instant controlled pressure drop; Water content; Practical freezing rate; Texture. 


\section{Introduction}

Freezing is a common fruit and vegetable conservation process that preserves the sensorial quality and nutritional compounds [1]. However, in the case of high-water-content perishable fruits and vegetables, the treatment is usually accompanied by irreversible damage of cell structures and possible deterioration of textural quality of the frozen products after thawing due to large ice crystals formed in the tissue during freezing process [2]. Dehydrofreezing which is a preservation process that involves partial dehydration before freezing can be used in order to diminish tissue damage [3-5].

The reduction in the product water content before freezing improves both freezing performance and product quality in the case of Golden delicious apples [6]. Process performance is revealed through an improvement of freezing rate and a decrease of freezing time [7] as well as lower energy consumption, lower cost of packaging, distribution, and storage. Whereas, quality improvement includes better preservation of structural and textural characteristics and decrease of thaw exudate water rich on soluble nutrients.

In the other hand, since the partially dried products are not yet microbiologically stabilized, subsequent treatment is necessary, before freezing, for product decontamination.

Likewise, to remove the impact of possible shrinkage of partially dried products instant controlled pressure drop (DIC) process is also required [8].

However, no work has been reported in the literature about mechanical properties after the combined process "air drying + DIC + freezing'. Hence, the main objectives of this study were to (i) establish a new freezing method, namely, DIC-assisted dehydrofreezing, and to (iii) assess and compare the impacts of water content and practical freezing rate on thaw exudate water and textural characteristics of dehydrofrozen products previously DIC treated.

\section{Materials and Methods}

\subsection{Process treatments}

Initial water content (W) of apple fruits (var. Golden delicious) was determined according to AOAC official method 934.06 [9]. It was of $700 \pm 10 \%$ dry basis (db). Discs of $10.0 \pm 0.2$ mm thick were prepared for process treatments and texture analysis.

\subsection{Partial drying}

Partially drying experiments were carried out in a airflow dryer under constant conditions: air temperature, air velocity, and air relative humidity of $45{ }^{\circ} \mathrm{C}, 2 \mathrm{~m} / \mathrm{s}$, and $12 \%$, respectively. Drying experiment was stopped once desired water content $(\mathrm{W})$ levels were attained (200, 100, and 30\% db). 


\subsection{DIC treatment}

Partially dried apple samples with different water contents (200, 100, and 30\% db) were DIC treated by an adequate equipment (ABCAR-DIC Process, La Rochelle, France).

\subsection{Freezing}

Partially dried and DIC treated apple samples at different water content levels were frozen in a freezer (Whirlpool Model AFG 363/G, Italy) with air temperature of $-30{ }^{\circ} \mathrm{C}$ at two different practical freezing rates;high practical freezing rate $(\mathrm{PFR}+)$ and low practical freezing rate (PFR-) depending on the thermal resistance established between the freezing airflow and the sample surface [7].

\subsection{Thawing process}

Completely frozen apple samples previously DIC treated were thawed in a refrigerator (FAR Model RT 140, Romania) at $4{ }^{\circ} \mathrm{C}$ overnight just before starting the textural measurements [6].

\subsection{Quality assessments}

\subsubsection{Determination of thaw exudate water}

Dehydrofrozen DIC treated-apple samples were used to measure thaw exudate water (TEW) expressed in $\mathrm{g} / 100 \mathrm{~g}$ water, during the thawing phase $[7,10]$.

\subsubsection{Texture measurement}

Textural firmness of DIC treated-dehydrofrozen/thawed apple slices was evaluated by measuring the maximum puncture force through a puncture test with a cylindrical puncture probe of $2 \mathrm{~mm}$ in diameter at a constant speed of $5 \mathrm{~mm} / \mathrm{s}$ using Instron Universal Testing machine (Model 5543, USA) [6].

\subsection{Statistical analysis}

Bifactorial analysis of variance and SNK test were carried out using the Statistical Package for the Social Sciences (SPSS) version 20.

\section{Results and discussions}

\subsection{Thaw exudate water}

The impacts of water content (W) of apple samples and practical freezing rate (PFR) on thaw exudate water (TEW) during thawing of DIC treated-dehydrofrozen apple samples were investigated and experimental results are illustrated in Figure 1. 


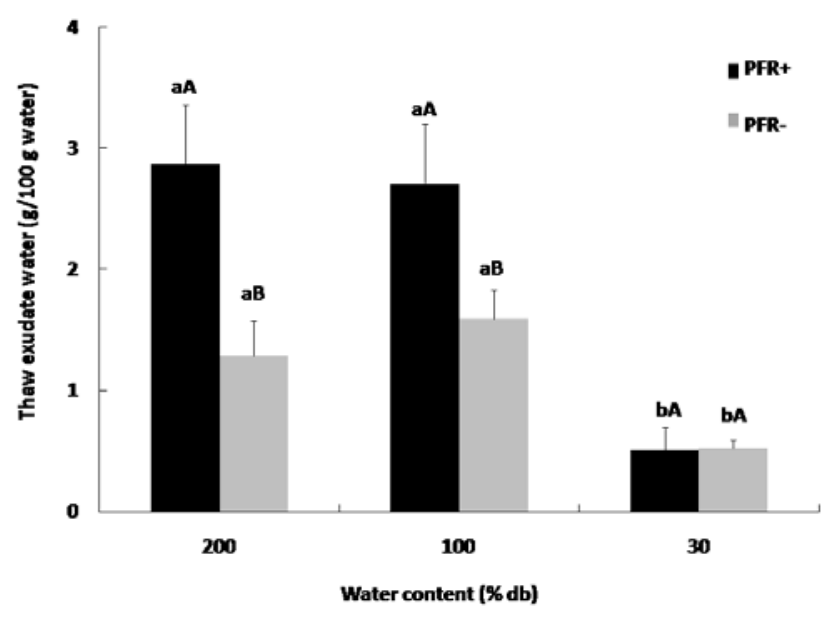

Figure 1. Impacts of water content and practical freezing rate on thaw exudate water (TEW) of DIC treated-dehydrofrozen apples. (Data are expressed as the mean \pm standard deviation. Values for the same practical freezing rate having the same letter $(a, b$ and $c)$ for thaw exudate water (TEW) are not significantly different at a confidence level of 95\%. Values for the same water content level having the same letter (A, B and C) for thaw exudate water (TEW) are not significantly different at a confidence level of 95\%).

Figure 1 shows the impact of the two different practical freezing rates on the thaw exudate water (TEW) of dehydrofrozen DIC treated-apple samples with different water contents (200, 100, and $30 \% \mathrm{db}$ ) during thawing process. Thaw exudate water (TEW) of $200 \%$ and $100 \% \mathrm{db}$ apple samples frozen at $-30{ }^{\circ} \mathrm{C}$ was approximately $3 \mathrm{~g}$ exudate water $/ 100 \mathrm{~g}$ water in the product at high practical freezing rate $\left(\mathrm{PFR}^{+}\right)$after thawing at a temperature of $4{ }^{\circ} \mathrm{C}$. Indeed, it was lower than $0.5 \mathrm{~g} / 100 \mathrm{~g}$ water for apple samples with $30 \% \mathrm{db}$ water content and frozen at the same practical freezing rate $\left(\mathrm{PFR}^{+}\right)$.

Previous researches have equally demonstrated that dehydration by hot air causes a diminution in drip loss during the thawing process in the case of dehydrofrozen strawberry and pineapple fruits [11,12]. These authors reported that air drying prior to freezing presents the advantage of decreasing the drip loss and the water exudate volume after thawing process as compared to osmotic dehydration [11,12].

As it is shown in Fig. 1, the higher the initial water content of dehydrofrozen apples, the higher the amount of TEW. Same results were obtained for several dehydrofrozen fruits such as strawberry, kiwi fruits, and pears $[13,14]$. The TEW decrease during thawing of DIC treated-dehydrofrozen samples may also be explained by a preservation of the structural and textural properties of apple samples as a consequence of the partial removal of water before freezing. 
In the other hand, the impact of practical freezing rate on thaw exudate water (TEW) was significant and very important for high water content samples (200\% and $100 \% \mathrm{db}$ ). It had less significantly detrimental effect on TEW for lower water content samples (30\% db).

\subsection{Texture variation}

The maximum puncture forces (firmness) after thawing of DIC treated-dehydrofrozen apple samples, which were frozen at two different practical freezing rates ( $\mathrm{PFR}^{+}$and $\mathrm{PFR}^{-}$) are shown in Figure 2.

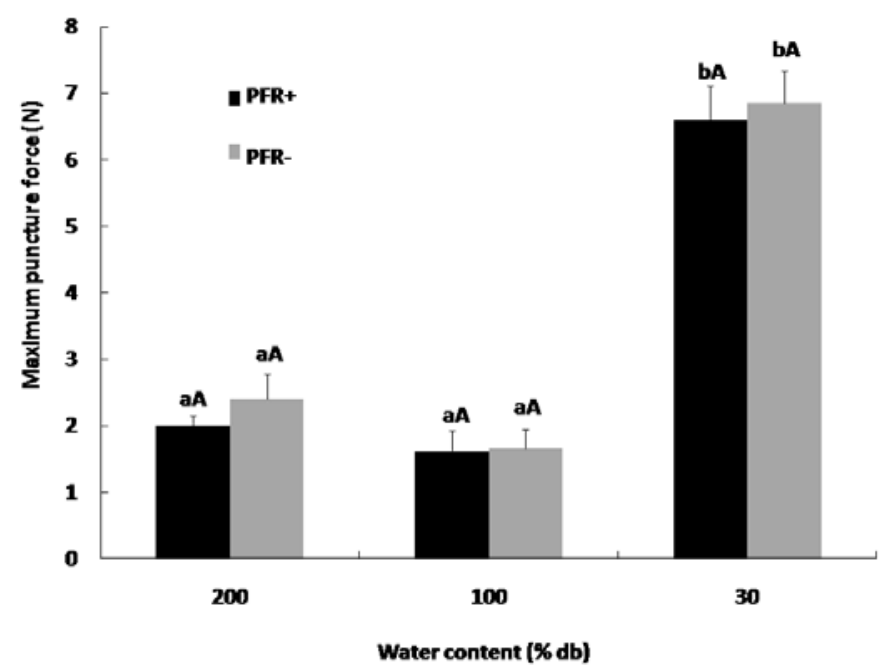

Figure 2. Impacts of water content and practical freezing rate on firmness of DIC treateddehydrofrozen apples. (Data are expressed as the mean \pm standard deviation. Values for the same practical freezing rate having the same letter ( $a, b$ and $c$ ) for maximum puncture force are not significantly different at a confidence level of $95 \%$. Values for the same water content level having the same letter ( $A, B$ and $C$ ) for maximum puncture force are not significantly different at $a$ confidence level of 95\%).

As it is shown in Figure 2, firmness (maximum puncture force) of DIC treateddehydrofrozen apple samples was constant (about $2 \mathrm{~N}$ ) for high water content levels of $200 \%$ and $100 \% \mathrm{db}$, for both practical freezing rates. It increased for lower water content to reach $6.5 \mathrm{~N}$ for $30 \%$-db samples, while no effect due to practical freezing rate was evidenced. ANOVA and LSD tests carried out for the firmness values statistically confirmed these differences. DIC-dehydrofreezing/thawing processes induced a significant $(p<0.05)$ increase of firmness with the decrease of sample humidity. Moreover, according to the result of the simple range test (SNK test), two homogeneous groups were identified. 
The first group includes $200 \%$ and $100 \%$-db apples. The second group only included samples with water content of $30 \% \mathrm{db}$.

These results confirmed that the significant impacts of water content on firmness obtained in the case of dehydrofrozen apples without DIC pretreatment, with also an insignificant effect of practical freezing rate. Firmness values of dehydrofrozen/thawed and non DIC pretreated apples were about 2, 4.5, 7, and $12 \mathrm{~N}$ for samples with water contents of 700 , 200, 100, and 30\% db, respectively [7]. Firmness of dehydrofrozen apples was found to be higher for samples non-DIC treated. This difference on firmness is explained by textural modifications caused by DIC treatment applied before freezing as texturing process [6].

Similar results, concerning the impact of air drying performed as freezing pretreatment on textural properties, were obtained for dehydrofrozen/thawed strawberry and kiwi fruits [11]. Airflow drying as freezing pretreatment resulted in dehydrofrozen/thawed products with improved textural properties and higher firmness. Indeed, the low water content of dried samples prevents the cell wall damage and preserve the product structure during freezing and thawing processes [2,6].

\section{Conclusions}

Fruits and vegetables present a category of food products which is characterized by high water content generally higher than $500 \% \mathrm{db}$. This category of agriculture products can also be characterized by initial microbial contamination. Partial drying coupled to instant controlled pressure drop (DIC) as adequate pretreatment should present an intensification way for fruit and vegetable freezing process. The coupling of these operations presents several advantages concerning the product stability through a partial removal of water and a decontaminating pretreatment.

Thaw exudate water for DIC treated-dehydrofrozen apples during the thawing was approximately $3 \mathrm{~g} / 100 \mathrm{~g}$ water for high water content samples (200 and 100\% db). Whereas, it was lower than $0.5 \mathrm{~g} / 100 \mathrm{~g}$ water for samples with $30 \% \mathrm{db}$ water content. The impact of practical freezing rate on thaw exudate water was significant only for high water contents. For low water content level ( $30 \% \mathrm{db}$ ), practical freezing rate became a less important parameter for freezing process.

Water content had a significant effect on the textural properties of apple fruits after DICdehydrofreezing/thawing processes. In fact, fruit sample firmness increased when water content decreased for both practical freezing rates. Whereas, practical freezing rate had an insignificant impact on apple firmness.

In conclusion, partial removal of water constitutes a promising solution to reduce the negative impacts of freezing on textural quality. This process coupled with a texturizing pretreatment, showing perfect decontamination effects, can be suggested as an innovative fruit and vegetable conservation process. This new method allow obtaining dehydrofrozen 
products with high textural quality after thawing and particularly without imposing a severe control of the partial drying step especially for the microbiological quality of products.

\section{References}

[1] Li, B., \& Sun, D.-W. (2002). Novel methods for rapid freezing and thawing of foods a review. Journal of Food Engineering, 54(3), 175-182.

[2] Wu, L., Orikasa, T., Tokuyasu, K., Shiina, T., \& Tagawa, A. (2009). Applicability of vacuum-dehydrofreezing technique for the long-term preservation of fresh-cut eggplant: Effects of process conditions on the quality attributes of the samples. Journal of Food Engineering, 91(4), 560-565.

[3] James, C., Purnell, G., \& James, S. (2014). A Critical Review of Dehydrofreezing of Fruits and Vegetables. Food and Bioprocess Technology, 7(5), 1219-1234.

[4] Cheng, L., Sun, D.W., Zhu, Z., \& Zhang, Z. (2015). Emerging Techniques for Assisting and Accelerating Food Freezing Processes-A Review of Recent Research Progresses. Critical Reviews in Food Science and Nutrition.

[5] Xin, Y., Zhanga, M., Xu, B., Adhikari, B., \& Sun, J. (2015). Research trends in selected blanching pretreatments and quick freezing technologies as applied in fruits and vegetables: A review. International Journal of Refrigeration.

[6] Ben Haj Said, L., Bellagha, S., \& Allaf, K. (2015). Optimization of Instant Controlled Pressure Drop (DIC)-Assisted Dehydrofreezing Using Mechanical Texture Measurements Versus Initial Water Content of Apple. Food and Bioprocess Technology, 1-11.

[7] Ben Haj Said, L., Bellagha, S., \& Allaf, K. (2016). Dehydrofreezing of apple fruits: Freezing profiles, freezing characteristics and texture variation. Food and Bioprocess Technology (FABT), Volume 9, Issue 2, 252-261.

[8] Allaf, T., \& Allaf, K. (2014). Instant Controlled Pressure Drop (DIC) in Food Processing. Springer.

[9] AOAC. 1990. Association of Official Analytical Chemists (15th edn), Helrich K (ed). Arlington: Virginia 22201, USA.

[10] Maestrelli, A., Lo Scalzo, R., Lupi, D., Bertolo, G., \& Torreggiani, D. (2001). Partial removal of water before freezing: cultivar and pre-treatments as quality factors of frozen muskmelon (Cucumis melo, cv reticulatus Naud.). Journal of Food Engineering, 49(2-3), 255-260.

[11] Sormani, A., Maffi, D., Bertolo, G., \& Torreggiani, D. (1999). Textural and structural changes of dehydrofreeze-thawed strawberry slices: Effects of different dehydration 
pretreatments / Cambios texturales y estructurales de rodajas de fresa deshidratadas y descongeladas: Efectos de diferentes pretratamientos de deshidratación. Food Science and Technology International, 5(6), 479-485, doi:10.1177/108201329900500605.

[12] Ramallo, L. A., \& Mascheroni, R. H. (2010). Dehydrofreezing of pineapple. Journal of Food Engineering, 99(3), 269-275.

[13] Moraga, G., MartíNez-Navarrete, N., \& Chiralt, A. (2006). Compositional changes of strawberry due to dehydration, cold storage and freezing-thawing processes. Journal of Food Processing and Preservation, 30(4), 458-474.

[14] Marani, C. M., Agnelli, M. E., \& Mascheroni, R. H. (2007). Osmo-frozen fruits: mass transfer and quality evaluation. Journal of Food Engineering, 79(4), 1122-1130. 